\title{
Influence of Canopy Structure of a Primitive Korean Pine Forest on Snow Accumulation in Xiaoxing'an Mountains of China and its Simulation Study
}

\author{
yang xiao ${ }^{1}$, shuping zhao ${ }^{2}$, guohua song ${ }^{2}$, and Yongliang $\mathrm{Li}^{2}$ \\ ${ }^{1}$ Heilongjiang University \\ ${ }^{2}$ Affiliation not available
}

May 5, 2020

\begin{abstract}
Snowfall, snow accumulation, and stand structure in a primitive Korean pine forest of the Xiaoxing'an Mountains, China, were assessed for 2 consecutive years. Moreover, a physical mechanism-based snow accumulation model, which can be applicable to stand-scale forests, was introduced to simulate snow accumulation in the studied region. The results showed that the mean atmospheric temperature was $-17^{\circ} \mathrm{C}$ during the snow accumulation period. Snow density was lower during snow accumulation period but slightly higher when snow melted. Moreover, when snow accumulated, snow water equivalent was significantly higher in forest clearings than beneath dense canopies, with a maximum difference of $>50 \%$. The variability of snow water equivalent in forest clearings was relatively low, whereas that beneath dense canopies was higher. The maximum snow accumulation in the forest indicated a significant negative correlation with canopy density, tree height, effective leaf area, and slope, whereas it indicated a significant positive correlation with canopy width. However, no significant correlation was noted between the maximum snow accumulation and diameter at breast height, basal area, or canopy height. The effective leaf area index and canopy density of the primitive Korean pine forest in this region could be well explained using a power function. As snow accumulated, the presence of forest canopy significantly affected the spatial distribution of snow accumulation in the forest. When snow melted, atmospheric temperature was the main factor controlling snow melting. Canopy density, slope, and canopy width showed a significant impact on maximum snow water equivalent; this factor increased with a decrease in canopy density and slope and with an increase in canopy width. In the present study, slope was selected as one of the main factors affecting snow accumulation in the forest. Therefore, future studies on snow accumulation models should incorporate slope as a parameter to improve simulation accuracy.
\end{abstract}

\section{Hosted file}

Influence of Canopy Structure of a Primitive Korean Pine Forest on Snow Accumulation in Xiaoxing'an Mou available at https://authorea.com/users/302581/articles/432891-influence-of-canopystructure-of-a-primitive-korean-pine-forest-on-snow-accumulation-in-xiaoxing-anmountains-of-china-and-its-simulation-study

\section{Hosted file}

Figure.rar available at https://authorea.com/users/302581/articles/432891-influence-ofcanopy-structure-of-a-primitive-korean-pine-forest-on-snow-accumulation-in-xiaoxing-anmountains-of-china-and-its-simulation-study 